\title{
How Do We Inhabit Openness?: Rethinking Volunteerism in the Context of Whole Person Education
}

\author{
John Nguyet Erni
}

\begin{abstract}
In this paper, I aim to advance a reframing of our understanding of "whole persons" in the well-established paradigm of Whole Person Education. At a time characterized by rising social conflicts and schisms, what would be an appropriate humanistic reimagination of a so-called wellrounded person? Drawing on the work of anthropologist Tim Ingold and using youth volunteerism as an exemplar of social practice, I propose the idea that a whole person, if achievable, is someone who inhabits "the open" as an unfolding, interconnecting, vibrant, and enjoyable horizon. Further, it is suggested that this open horizon moves with, and is moved by, strangers. It is hoped that an epistemology of the open that embraces stranger relationality, in the form of volunteerism or any other related social practices, will help us move toward a new whole personhood.
\end{abstract}

Key words - ecological psychology; stranger relationality; whole person education; youth volunteerism.

\section{INTRODUCTION}

This paper represents an opportunity to think about the important but slightly peculiar idea called "whole person education." My interest is drawn to the notion of the "whole person." Let me first make, without ambiguity, the following shocking declaration: there is no such thing as a whole person. It is mostly an aspiration. While it is crucial for us to have this aspiration, we should not confuse this possibility this immanence - with the socially constituted reality of personhood. "Personhood" is neither a relatively fixed, complete entity (in the classical definition of humanity), nor the ephemeral, always shifting, performative construction (as professed by the deconstructionists). The main question that drives this paper is: how do we inhabit personhood in an open manner, acknowledging that incompleteness is a gift? Or more broadly, how do we inhabit openness in an unfolding, interconnecting, vibrant, and enjoyable horizon?

How often have we encountered the saying "to be open"? In the education environment that we find ourselves, we develop our pedagogical vision around the need to train our students to be open-minded individuals who are, ideally, cross-culturally exposed, multiply linguistically competent, and globally actionable. In modern education, to meet the challenges of this increasingly complex world, we liberal thinkers form our curricula around "the open," through theoretical variants like comparative culturalism and moral variants like diversity training. This is all good, and I

Published on August 20, 2021.

J. N. Erni, Hong Kong Baptist University, Hongkong.

(corresponding e-mail: johnerni@hkbu.edu.hk) thoroughly support these ideals. Indeed, we all know what it feels like to liberate our minds from the dreads of parochialism. How much suffering, warfare, and social conflict arise from ethnonationalism, provincialism, nativism, and fundamentalisms of various shades and forms? We would not have arrived at our modern liberal university life, as we know it, if we had not fought hard and won the battle to liberate our education toward the vision and practice of cosmopolitanism, broadly defined.

Yet once we attempt to pinpoint "the open" within customary conventions of thought, no experience could be more elusive. What and where is the open? Does it circulate in the deliberative classroom where debates take place, in the student unions and reading groups where formative ideas take shape, or in yet undefined wayward itineraries of overseas exchange experiences? Are these the same or different? If the ambience of globalization encircles our educational planet, and the sky of cosmopolitan diversity arches above our heads, then in what shape or form can the person (who aspires to be "whole") exist in relation to them? How, in other words, can we inhabit the open?

Here, I suggest that instead of thinking of our inhabited society as composed of exclusive spheres of the self as an entity surrounded by familiar faces of our friends, family, and intimate partners, separated by the degree of exposure to education, we need to attend to the fluxes of strangers. Moreover, we need to learn to form relationships with them. I want to contrast our comfort zone of imagined wholeness populated by the familiar, with the search for another feeling through making external, tactile contact with the unfamiliar in our surroundings and to mingle with those unacquainted, even unknown, elements. To cite British anthropologist Tim Ingold who studies environmental psychology, "as we live and breathe, the wind, light, and moisture of the open sky bind with the substances of the earth in the continual forging of a way through the tangle of life-lines that comprise the land" [1, p. 115].

\section{II. "THE OPEN" IS AN EXPERIMENT}

If I ask you to draw the open sky, what would you put on paper? The cognitive relationists might quickly come to the realization that to draw the open empty sky, you would have to outline its relation to other objects, such as clouds, rainbow, and of course objects on earth from which the sky can be observed. The spiritualists may suggest that drawing the sky is impossible; the empty space is best left to

This work described in this paper was fully supported by a General Research Grant from the Research Grants Council of the Hong Kong Special Administrative Region, China (Project No. 12607618). 
meditative flights of imagination and mindful visualization, and not to the boundedness of lines and shapes that we could put down on paper. Tim Ingold, the British anthropologist I cited earlier, relates to us some of the debates in the fields of cognitive and developmental psychology concerning how children learn the shape of the earth. He uses these debates in experimental child psychology to illustrate a problem relevant to drawing the sky.

Ingold [1] tells us that a number of studies has challenged fundamental presuppositions that children everywhere, regardless of cultural background, initially bring to their cognitive reasoning about the earth [1, pp. 99-114]. These presuppositions are, firstly, that the ground is flat, and, secondly, that unless supported, things fall. Therefore, the most common representation often presented to school children, of the figure of a spherical earth upon which stands the human figures, animals, plants, houses, etc., would render those two presuppositions incorrect. This is because in this kind of typical picture, the ground is not flat and gravity does not apply, since some of the figures on the round edges would have fallen off the earth!

It is argued that to grasp such a counter-intuitive understanding that the earth is round like a ball and that people and other organic beings can live anywhere on its surface without falling off, calls for a completely new conceptual understanding of the child's mind. Here it can be said that we encounter the classical and longstanding debate in psychology about whether knowledge acquisition in children is strongly constrained by their innate, so-called "naïve" mental structures or more dependent on sociocultural contexts of learning. In other words, do we possess some intuitive understandings of the world as children, based largely on experiences through our sight, hearing, smell, and tactile contacts, understandings that may be distorted by subjective perception and would thus color our subsequent cognitive development? Or, as we grow up, did we begin with a sort of open mind, a proverbial blank sheet of paper, upon which knowledge is grafted, bit by bit? Both accounts, representing the intuitionist and the developmentalist camps respectively, are obviously correct. This is my humanist side speaking, which believes that we grapple with the world through our intimate immersive experience in it as well as the scaffolding of various fragments of knowledge from the social and cultural spheres through time and space. I want to locate the question of "inhabiting the open" in this double imagination, and I do that by recalling an aspect that Tim Ingold has cast his thinking upon as well. I share his insight that when a child is asked to think about the shape of the earth, he/she combines an intuition based on their grounded experiences and their manner of adding in more layers of understanding of the earth through learning. But what binds intuition with learning, phenomenological experience, and the constructivist acquisition of knowledge? Here, Ingold provides a brilliant insight.

He cites two examples of children's drawing of the earth [1, pp. 101-105]. There is, first, a drawing by a 6-year-old boy, who told the research assistant that the earth was shaped like a ball. To see it one should look downwards at the ground. In addition, the earth was completely surrounded by space. After asking him to draw the earth, the research assistant invited the boy to draw the sky. A little confused, the little boy said: "The sky has no shape." He went on: "Do you mean space?" Nevertheless, he proceeded to draw a ring around the round shape that depicted the earth. To him, the sky was something that enveloped the earth, as represented literally by a ring drawn around the round-shaped earth. According to Ingold, this experiment tells us that to understand the earth, one also needs to attend to the nature of the sky, and how the ground is the connector between the two. Their surfaces, as it were, are all interfaced.

In the second example, a 9-year-old girl drew a round earth, with the moon and some stars added beside it. Like how he asked the boy, the research assistant invited the girl to draw the sky. And like the boy, she frowned and looked confused. After pondering for a while, the little girl proceeded to sketch some roughly horizontal lines near the top of the paper, which looked much like a cloud-base. The cloud-like drawing sat above her sketch of the earth, moon, and stars. "Where do people live in this drawing?" the researcher asked the little girl. Her answer was to draw a house whose base lied along the lower border of the paper. The research assistant wanted to press her a little further, to which she responded by drawing another house. On the third request, the girl eventually gave in to the researcher's implicit demands. She rubbed out one of her houses and drew a stick figure upon her round earth. But this only instigated a further bout of interrogation. Pointing at the sketch of the remaining house after the other one was erased, the researcher asked, "This house is on the earth, isn't it?... How come the earth is flat here but before you made it round?"

By associating the bottom of the drawing paper as the ground, the girl defended by saying she was right by drawing the house there. Confirming with the girl that the ground was flat, the researcher asked: "But the shape of the earth is..." And without any hesitation, the little girl replied, "Round."

One might sympathize with the researcher's feeling that the little girl was being thoroughly inconsistent, who wavers between her opposite conceptions of the earth's surface as being round and being flat. Yet Tim Ingold argues that the researcher failed to realize that the little girl was actually rather consistent in applying a distinction between two entities, namely the (round) earth and the (flat) ground [1, p. 102].

These examples were used to illustrate some of our cognitive confusion as inhabitants of the earth. First, we waver between objective science and subjective experientially formed knowledge. Second, while the inhabitants know a great deal about our earthly surroundings, which include the flat ground, the ocean, land, houses, and people, their ability to articulate what the sky is, is much weaker. Indeed, we know how to draw the stars, clouds, and moon. But the way we imagine the sky is but a mirror image of how we interpret the earth: it is furnished by various objects. Third, and this is the most important hidden problem, Ingold argues, which is that most of us fail to see that understanding of the earth is dependent upon understanding of the sky, and vice versa [see also 2]. Most of us are quite literally "stuck" on the ground, which we understand to be the surface that connects the earth with the sky. Stuck and earthbound, our faint understanding of the sky and the elements in it, would give us a metaphorical problem of some great importance. 
So, let me come back to earth, so to speak! It seems to me that from an eco-psychological perspective, the notion of the "whole person" should be reframed as one who can navigate among the groundedness of our lived experience, the boundedness of society, and the openness of a seemingly boundless horizon. I am intrigued by the idea that this open horizon shifts with, and is shifted by, strangers. However, most of us are creatures who shifts with, and are shifted by, the familiar. In ordinary circumstances, our environment, which ought to be conceived of as an interesting, unbounded horizon, is often cluttered by familiar objects. The "furniture" that forms our society, confines us but also makes living possible. In these terms, a boundary-less horizon would be uninhabitable, and often arouse fear of the unknown. As a result, we roam the earth as if on a stage set, and in this way, we are fated to pick our way amidst the clutter of the world [see also 3]. Let me now turn to another interlocutor who, in a recent research project, has given me some important insights relevant to those questions of boundary, openness, and the possible relations we might have with total strangers.

\section{Youth Volunteerism: The CASE OF VolTra}

About two years ago, I encountered a Hong Kong-based organization that provides young people around the world with volunteering opportunities. Combining volunteer work with traveling, VolTra is an organization whose very name combines the involvement of volunteer labor, especially community services, and the joy of traveling. Established in 2009 , it is a unique non-governmental organization of its kind in Hong Kong. By its $10^{\text {th }}$ anniversary in 2019, VolTra has offered over thousands of international and local workcamps and voluntary service projects in over 85 countries each year. It does so either on its own or coordinate with similar youth volunteer organizations in foreign countries. VolTra workcamps have covered the Asian region (e.g., India, Taiwan, Japan, Mongolia, Cambodia, Nepal, and Thailand) and in Europe, Latin America, and Africa. In 2018-19 alone, close to 1,500 "VolTrateers" from Hong Kong have participated in a wide range of global and local actions. Due to the disruptions of the global COVID-19 pandemic, which halted international travels, VolTra had had to revamp its vision through mainly organizing online activities for both local and international youth [4].

Our research on youth volunteerism stemmed from the interest in observing the trend of young people flocking to participate in international volunteer work, in an age of diminishing economic opportunities and broken promise by many governments, leading to widespread distrust of authority and of anything that bodes quixotic dreams for the young generation. We were compelled to ask: has there been a sort of resurgence of youth idealism in spite of the cruel reality of social disillusionment and economic precarity? [5][7]. Are we, in a sense, in the "new 1960s"?

However, participation in volunteering work when combined with traveling and sightseeing has attracted criticism. The critique of this growing phenomenon largely centers on two kinds of suspicion: the participants' amateur background (implying a dearth of professional working experience, knowledge, or skills in community revival work) and their privilege (suggesting that their "benevolence" in helping the host communities is part of their "touristic gaze" enmeshed with a first world "imperial impulse") [8]-[15]. While some of our informants from Hong Kong were aware of these problematic underlying impulses, their profile, however, shows that many of them are in fact preprofessionals who have slipped through the cracks of a precarious economic system, including "students who study in non-award courses overseas, and semi-employed or out-ofwork youth who have not been able to secure full time employment at home" [10, p. 916]. Without dismissing the criticisms of amateurism and possible first-world "savior complex," we argue that we need to reflect on the unique kind of social and cultural capital they can bring to the encounter with strangers in the workcamp setting. We also need to understand the forms of "cultural translation" they are able to practice and the degree of openness they can develop in their international encounter. VolTra [16] makes known their purposes for workcamp participants, which includes

- "getting yourselves ready for the "modern jobs": this denotes the increasing possibility of having to engage with non-traditional "9 to 5 jobs," with the requisite ability to be flexible, adaptable, and willing to work with and relate to many people of different background;

- "exploring the world with other change-makers in the glocal community": this indicates a motivation to make changes beyond one's "comfort zone" and beyond mere "good intentions";

- "gaining more sustainable resource and achieving a greater dream": this suggests the possibility of acquiring new skills and cultural capital that can only be developed in mobile settings;

- "staying well and powering up yourself for the coming journey": this beckons the need for an open attitude, including the need to learn how to encounter and engage with total strangers well beyond one's social circle.

No matter how complicated their motivations are when deciding to embark on volunteer work, their predicament needs to be better theorized in our study. In other words, the common critiques of voluntourism, while valid, might have overlooked the complexity, if not struggles, brought about the youth's own journey beyond their common routines and life situations. Let us take a closer look at one example.

\section{A. Sara: Establishing "Real/Wheel Power"}

Sara, who was still in college in 2012, applied to the Physical Handicapped and Able-Bodied (PHAB) workcamp in Switzerland as her first VolTra experience. The story below originates from an in-depth interview we had with her in mid-2020. Between 2012 and 2020, Sara had engaged in VolTra's local and overseas activities multiple times.

Sara was clear about why she chose VolTra: the meaning she sought through volunteering and the low travel cost. In addition, as a student of physical therapy in college, Sara had become more and more disillusioned about the hospital system during her internship experience in Hong Kong. There, she witnessed the frailty of human life and was especially concerned about the distressing situation when patients had to be forced to leave the hospital before they had fully recovered. Attracted by the language of "change making" in VolTra's workcamp programs, Sara went away in 
search of other kinds of healthcare-related experiences in a foreign country. Sara joined a program called "Access for All," which was in a little wooden hostel run by an NGO supporting the deaf community in Switzerland.

She joined a team with ten other volunteers from Asia and Europe, which included a deaf woman from Japan, a blind woman from Slovakia, and a near-blind local woman. The volunteer work was mainly some common daily tasks, such as sweeping in the hostel, fixing the garden road, and cleaning rivers. One day, when they were planning a walk to the lake, the deaf woman from Japan named Riko appeared very agitated about something, and she refused to go out with them. Riko even expressed that she wanted to leave the workcamp. Infuriated, she found the Info-sheet and pointed to the team about the camp rule to care for and help each other. Somehow, her camp experience had been disappointing. The teammates had had difficulty communicating with her due to her disability, until a team member Sandy, who was blind, intervened. The conflict was not resolved until Sandy (who was blind), intervened. Amazingly, Riko and Sandy managed to talk things over with the help of technology, and eventually Riko was consoled, and she calmed down. Sara depressingly said, "This incident made me feel bewildered and utterly useless." She continued:

I thought my experience of treating the handicapped could help me understand them better, but the fact is that they all have their own ways to manage their lives, their needs, and where things are sensitive. (personal interview)

In other words, the volunteers' prior "professional training" did not necessarily help them foresee the actual difficulties that may arise when people were away from their familiar surroundings. The tension she and the others experienced renders their co-living a reflective existence, especially around the question of disability and what kind of social integration could comfortably take place between the able-bodied and the disabled. Experiences such as the one narrated above shifted Sara's approach to health therapy. Instead of only focusing on healing patients in the hospital, Sara saw a much greater need for the disabled to live well outside of medical facilities. She recalls:

I feel happy that I chose to work in an NGO, because it provides long-term service for patients. This choice has to do with the experience I gained from the VolTra workcamp, because when in the workcamp I lived with them and learned that the disabled people had their own lives besides their treatment part in the hospital. When we talk about quality of life, what I understand is their life, and not only the part about treating their illness...Sadly, the medical system in Hong Kong is too institutionalized. Everything is standardized. Patients with varied symptoms often only receive standard treatments regardless of their life needs. (personal interview)

Subsequently, Sara joined a number of overseas workcamps organized by VolTra. In one of her multiple trips, she encountered another situation that even led her to question the operations of workcamps. During a program in Vietnam, Sara was supposed to work with an NGO set up to assist disabled children. However, shortly after she arrived, she realized that there were many more volunteers than the children they were supposed to serve. When it became clear to her that the organization was more interested in recruiting a large number of volunteers from international organizations like VolTra, and therefore earning a higher hosting fee, than actually working to improve the children's lives, Sara concluded that "their thinking is that those children are meant to stay here forever!" (personal interview). She called the organization "black-hearted," which meant inauthentic and exploitative in Chinese. With the other volunteers' consent, Sara reported this issue to VolTra and suggested that it ceased to work with this Vietnam-based NGO. As a result, VolTra did not only remove it from NVDA's (Network for Voluntary Development in Asia) membership network, but it also performed an overall review of partner integrity in the system. Sara's action may have made it more difficult for VolTra and NVDA to access the Vietnamese partners, yet the whole incident suggests how VolTrateers can play an active role in improving the organization's operations. Because of her participation in multiple workcamps over several years, Sara later became a Board Member of VolTra.

After her days with VolTra, Sara continued to explore ways to make society more inclusive for people with disabilities. Developing into a disability rights campaigner, Sara launched a community-based project called "Wheel Power Challenge (WPC)" in 2014. Supported by VolTra, Sara hailed the slogan of "wheel power for the disabled is real power." Sara and her wheelchair-user partners embarked on a hiking trip by wheelchair, yet as expected, everywhere they went they encountered obstacles, whether when they were trying to move up or down the hill or any slopes. Through the actual hiking experience, Sara wanted her participants to have a first-hand realization of how invisible wheelchair users' hardship was in public space.

Sociologist Ronald J. Berger reminds us:

Activists in [the disability] movement challenged characterizations of the disabled as abnormal, inferior, or dependent people who at best should be pitied or treated as objects of charitable goodwill. Instead, they advanced a "social model" of disability, claiming it is not an individual's impairment but the socially imposed barriers that construct disability as a subordinate social status and devalued life experience. Adopting the discourse of identity politics and multiculturalism, they challenged societal notions of normality and promoted disability as an acceptable, even celebrated, form of social difference [17, pp. 647-648].

In pragmatic terms, Sara realized that though she could not remove or change the obstacles on the road or in buildings, her team could change the way the wheelchair users move. She was convinced this would be the core contribution of the WPC project. Sara said, "My patients would not likely recover after leaving the hospital, and I think this is not their problem. It is the way social space is designed, along with certain limited ways of thinking of many people in our society, that made the disabled less willing to go outside" (personal interview). 
Her team focused on two elements in their project: the training and mapping sections. In the training section, volunteers were asked to use wheelchairs to move around in the city to gain experience of the concrete situations that wheelchair users often face. In the mapping section, they would gather barrier-free information, including the locations of, and routes to, barrier-free facilities, and then uploaded this information onto open-source mobile apps, such as Wheelmap.

\section{B. Sara's Open Horizon}

Sara's project demonstrates how human intervention and solidarity can counteract social exclusion. Wheel Power Challenge (WPC) has become a well-known non-profit initiative: "Through organizing various experiential programmes, we believe it can challenge our stereotypes and bring about insights into the connections of the environmental design and our everyday life. It drives advocacy for a more barrier-free society" [18]. Since its establishment in 2014, WPC has organized over 50 experiential programs involving more than 1,000 participants.

Sara's accumulated experiences through voluntary projects and leadership formation is a far cry from the so-called professional training she received in her college years. Through embodied knowledge and passion for making change, she defies the abstract schemes of integration and assimilation she learned from the medical and social welfare systems in Hong Kong.

What, we may say, is Sarah's open horizon? To her, the professional scientific method of treating patients provides an account of care that, like the objective account of the shape of the earth, cannot readily accommodate the phenomenon of the sky. For in relation to the sky, the earth can exist only as a flat ground of habitation. Her experience sheds light on the realization that a ground populated solely by the so-called professional people and objects can exist only within a simulacrum of the world, modelled in a familiar interior space. Sarah shows us that in the open world, beings relate not as closed, objective forms but by virtue of their common immersion in the fluxes of strangerliness. Her particular devotion to the disabled, through a special understanding of how surfaces of the disabled body interact with the surfaces of the wheelchair, which in turn interact with the rugged terrain of the slope of the road, has taught her the lesson that to inhabit the open is to dwell within a strangerly world in which every being is destined to touch and combine various mediums of otherness, near and far, in the continuation of its own existence. To resort to the metaphor we have been using, to know the sky to lift our gaze upward and around, we must feel the strange but enlivening sensations of the wind, rain, sound, and light, which are strictly not objects in the sky, but that which comes and goes as open, moving elements in our environment, which are unpredictable and sometimes scary.

\section{STRANGER RELATIONALITY}

I can relate to Sarah's story, partly because of my own ongoing thinking on the ethnic minority question in Hong Kong. Over the past ten years, I have been finding a way to think about the unique contour of race, ethnicity, and racism in Hong Kong's cultural history, in colonial formations, in the politics of the Cantonese language, in mass media especially visual representations, and in human rights law and policy [19]. I propose that the best sociocultural and political language with which to talk about the problem of race, is in the theorization about stranger-relations.

Yet in a metropolitan setting like Hong Kong, there seems to be a strange silence on the question of strangers. Encountering strangers is very much a taken-for-granted experience in the hustles and bustles of city living. Urban dwellers are also known to pass by one another, without attention, not to speak of effort, to reduce the feeling of strangeness toward one another. Without fanfare, the stranger is merely an untouched creature. They move about as if elements in the air.

In a more social and political register, many places around the world have had to grapple with the politics of strangerrelations, as dissatisfaction has been more and more vocalized. Social antagonism with "stranger effects" has been developed from deeply divided value conflicts (e.g., urban versus rural values; developmental against preservationist values; racially divided values, and so on). In Hong Kong, a distinguishing character of democratic politics over the past decade has been the making of "stranger-identities" [19]. From the infamous and ubiquitous "post-80s generation" student activists (implying immaturity and recklessness), the disgruntled working class, the ethnic minorities, the "vulgar" legislators, the agitative journalists, to the "riotous" youth, what we see is the ever-deepening schisms that render the city a fractured place marked by stranger-alienation everywhere [20]-[23].

Whether it is the stranger who tends to be reserved, silent, reticent, or conceding to differences (thereby provoking our indifference), or the stranger who is demanding, agitative, or mercilessly vocal (thereby stirring either our sympathy or rejection, depending on which political camp you're in), stranger-identities proliferate like the moving wind, rain, light, or sound that animates our environment. They mediate our relation between the ground we stand on and the open sky of which we are also inhabitants. In an important way, we are not "exhabitants" of the sky; even though we may treat the sky as "just space." I suggest that we need to know more about the strangers in our midst, and we need to develop a relation with them, in our ongoing contemplation about how to pry an open horizon in and beyond our society and world, in the pursuit of whole personhood. In my research on migrants and ethnic minority settlers, I find it increasingly important to have to dream of the city anew as a space of meeting strangers, through actively theorizing the problems of everyday ethnocentrism and racism, the promises and perils in our investment in the discourses of "the native" and "the local," and of "Chineseness" as the center of racial and ethnic belonging and exclusion [19].

\section{A. Who is a Stranger?}

"Stranger" stems from Old French estrangier, meaning "foreigner." Latin used the adjective extraneus as a noun to mean "stranger." The etymological sources suggest rather consistently that the stranger is an outsider. It was not until sociologist Georg Simmel [24]-[26] that we began to acquire 
a social definition of the word. In his survey of the various sociological imaginations of the stranger in the $19^{\text {th }}$ and early $20^{\text {th }}$ century, Simmel views the stranger as someone who is situated in a "unique synthesis of proximity and distance," in what he calls "halfway, unclear relations... which have their root in a twilight condition of feeling whose outcome might be hatred almost as easily as love" [27, p. 80]. There are three brief observations we can make of his formulation here. First, Simmel conceives of the stranger as a sociological category, and not some inner psychological or mental construct implying the private feeling of alienation. Second, to him, the stranger is not just the other; they are not mere outcasts completely devoid of any relation with the local or the native. Third, the two observations above help to derive an understanding of Simmel's important idea that the stranger is someone "useful" within the sociological imagination. His belief in the stranger as someone situated in "halfway, unclear relations" in fact gives the stranger a unique advantage unavailable to the native/the majority/the local. Researchers have looked at specific social domains where the strangers and their activities are not only present but in fact constructively needed [28], [29]. The stranger exists not because of their deviance, eccentricity, or abnormality, but because of the way they rework the social and cultural boundaries through Simmel's seminal conceptual categories of "sociation," "interaction," and "intersubjectivity" [30]. They are the medium that comes to change the dynamics of a social environment, and then they move on, circulate, and make various perceptible and imperceptible impact.

Karakayali, among other researchers, helps to decipher the ways in which the strangers answer certain social needs throughout history [27]. Specifically, he develops a general framework for analyzing the "uses" of the stranger in four major domains, including legal arbitration; the circulation of goods, money, and information; the management of sacred/secret domains; and also, what he calls the "dirty jobs" (e.g., menial labour). Throughout, we gain the idea that the stranger serves as a "social buffer" between the center of power in society and the marginal spaces to which power does not want to come close. In global times, they circulate between cultures without feeling the need to attach themselves to provincial local identity. As always, the emphasis is on the in-betweenness that they occupy.

\section{B. Encountering Total Strangers}

Returning to the sky, strangers are like clouds. Strictly speaking, clouds are not objects. Each cloud is, instead, a vaporous swelling that floats in the currents of the medium. To observe the clouds is not to see them as if they were the "furniture" of the sky, but to catch a glimpse of an ephemeral sky-in-formation, never the same from one moment to the next. They can also be thought of as stars. Stars, whatever their astronomical significance, are perceived not as objects but as points of light. In all, the open world, however, has no insides or outsides, only comings and goings. Such productive movements may generate swellings, growths, and occurrences, but not objects.

But we typically get a different account of, and have a different set of feelings toward, the stranger. We equate the stranger with the unknown, and often generate fear toward them. This is because we treat them as objects, and neglect to understand and feel the perceptible and subtle effects they bring to our ambience.

About the positive story I told you earlier about the young travelers who do volunteer work abroad, of course, in much of the literature on volunteer tourism, this practice has been thoroughly criticized. Critics say voluntourism has been tainted in different degrees by the complex of commercial, extractive, and neoliberal interests [8]-[15]. This broadstroked observation points neither to invasion nor to conquest as seen in the earlier eras, but to a certain form of adaptability that is now underwriting certain modern global economic and cultural logics. What these critiques of volunteer tourism often neglects is the inventiveness that is generated when the volunteer encounters total strangers.

\section{CONClusion: ANother Community Is Possible}

In our research with the VolTrateers, we learned many of them graduated from university with specific career paths in mind: as teacher, physiotherapist, radiotherapist, interior designer, accountant, and so on. However, their wayward journeys for workcamp experiences in far-flung places was shifted their life goals. They shared with us that the career paths that they formerly held only gave them an illusory promise of a "decent and stable life." Bird Tang, VolTra's Executive Director, suggested that organization existed to support those who had forsaken the ordinary middle-of-theroad mentality. Tang even goes so far as to say: "In my opinion, they all despise mainstream values (不屑主流的價 值)." He discovered that the key vocabulary of the VolTrateers tends to be “more possibilities” (更多可能性), “breaking through oneself” (突破自己), and “leaving the comfort zone" (出走comfort zone). An example of how the stranger can help to shift the ground upon which we stand comes from one of our informants. Wendy, aged 21, waxed philosophical about her volunteer experience in Kenya:

I don't appreciate people who stare at their cell phones all the time. In Kenya, there were not too many material things, so the children there spent time enjoying playing with each other, living happily “in the moment” (享受當 下). I admire the fact that these kids from poor regions made use of every little piece of resource they have to play, and also the fact that they were so connected to the earth (與土地有連結). They played with what they had, unlike us, who spend so much of our time and money on fake happiness. (personal interview)

What Wendy said seems to contradict the criticism of commercialism and depoliticization that many critics make of voluntourism.

Another informant, Alex, aged 34, had his own epiphany during his encounter in Africa:

Before I started working in the camp, the local volunteers showed me the slum area. The condition there was so impoverished yet the kids there were so happy...They were giddy when they saw us coming, and we took pictures together. This feeling - how to put it - was 
beyond words, it totally changed my understanding of the poor. To be honest, I was so ashamed that I had anticipated they would ask me for money...I prejudged them (帶著有色眼鏡去看待). (personal interview)

VolTra has redefined the meaning of traveling, as it has the profound value of meeting strangers.

Thus, I conclude with a proposal for rethinking what we mean by whole person education. The idea is that a whole person, if achievable, is someone who inhabits the open. In it, there are no hills, only the rising up of hills, which you will experience by touching their surface or climbing them. There is no fire, only the burning of fire, as you will find out from their flickering flames, the swirling of smoke, and the warming of the body. In the sky, the sun and the clouds are, respectively, their shining and billowing, just as the hills are their rising, and the fire is its burning. It is where all the action is.

Philosopher Alphonso Lingis in his book The Community of Those Who Have Nothing in Common [31] writes:

Beneath the rational community...is another community, the community that demands that the one who has his own communal identity, who produces his own nature, expose himself to the one with whom he has nothing in common, the stranger. This other community is not simply absorbed into the rational community; it recurs, it troubles the rational community, as its double or its shadow. This other community...is not realized...in producing something in common but in exposing oneself to the one with whom one has nothing in common: to the Aztec, the nomad, the guerrilla, the enemy...Community forms when one exposes oneself to the naked one, the destitute one, the outcast, the dying one [16, pp. 10-11; see also [32].

It is, I hope, a kind of strangeness that you can learn to live with.

\section{ACKNOWLEDGMENT}

The author thanks Prof. Roland Chin, former President of Hong Kong Baptist University, for his steadfast support of my research.

\section{REFERENCES}

[1] T. Ingold, Being Alive: Essays on Movement, Knowledge and Description, New York and London: Routledge, 2011.

[2] M. Heidegger, Poetry, Language, Thought, trans. A. Hofstadter, New York: Harper and Row, 1971.

[3] J. J. Gibson, The Ecological Approach to Visual Perception, Boston, MA: Houghton Mifflin, 1979.

[4] VolTra, Annual Report, 2018-19, 2020. Available: https://issuu.com/voltrahk/docs/voltra annual report 2018-2019.

[5] J. Butler, Precarious Life: The Powers of Mourning and Violence. London/New York: Verso, 2004.

[6] C. Han, "Precarity, precariousness, and vulnerability," Annual Review of Anthropology, vol. 47, issue 1, pp. 331-343, 2018.

[7] G. Standing, The Precariat: The New Dangerous Class. London: Bloomsbury, 2012.

[8] V. Amit and P. G. Barber, "Mobility and cosmopolitanism: Complicating the interaction between aspiration and practice,' Identities, vol. 22, issue 5, pp. 543-550, 2015.
[9] N. Coren, and T. Gray, "Commodification of volunteer tourism: A comparative study of volunteer tourists in Vietnam and in Thailand," International Journal of Tourism Research, vol. 14, issue 3, pp. 222234, 2012.

[10] J. N. Erni and D. Leung, "The dilemma of mobility: On the question of youth voluntourism in times of precarity," Cultural Studies, vol. 33, issue 6, pp. 915-943, 2019.

[11] J. Kushner. (22 March 2016). The voluntourist's dilemma. New York $\begin{array}{lll}\text { Times } & \text { [Online]. Available: }\end{array}$ https://www.nytimes.com/2016/03/22/magazine/the-voluntouristsdilemma.html.

[12] N. G. McGehee, "Oppression, emancipation, and volunteer tourism: Research propositions," Annals of Tourism Research, vol. 39, issue 1, pp. 84-107, 2012.

[13] L. Occhipinti, "Not just tourists: Short-term missionaries and voluntourism," Society for Applied Anthropology [Online], vol. 75, issue 3, 2016, doi:10.17730/1938-3525-75.3.258.

[14] K. Simpson, “'Doing development': The gap year, volunteer-tourists and a popular practice of development," Journal of International Development, vol. 16, issue 5, pp. 681-692, 2004.

[15] W. Vrasti, Volunteer Tourism in the Global South: Giving Back in Neoliberal Times. New York: Routledge, 2013.

[16] VolTra home page: https://voltrahk.learnworlds.com/home.

[17] R. J. Berger, "Disability and the dedicated wheelchair athlete: Beyond the "supercrip" critique," Journal of Contemporary Ethnography, vol, 37, issue 6, pp. 647-678, 2008.

[18] Wheel Power Challenge home page: https://wheelpowerchallenge.org.

[19] J. N. Erni, "Who needs strangers?: Un-imagining Hong Kong Chineseness," Chinese Journal of Communication, vol. 5, issue 1, pp 1-10, 2012.

[20] S. C-K. Chan, "A Hong Kong critique of identity: Belonging and becoming in the aberrant post-Colony," Situations, vol. 13. no. 2, pp. 169-197, 2020.

[21] N. Ma, "Changing identity politics: The democracy movement in Hong Kong," Citizenship, Identity and Social Movements in the New Hong Kong, edited by Wai-man Lam and Luke Cooper. New York and London: Routledge, pp. 34-50, 2018.

[22] R. Milkman, "A new political generation: Millennials and the post2008 wave of protest," American Sociological Review, vol. 82, no. 1 pp. 1-31, 2017.

[23] L-K. Pang, The Appearing Demos: Hong Kong during and after the Umbrella Movement. Ann Arbor: University of Michigan Press, 2020.

[24] G. Simmel, "The stranger," In D.N. Levine (ed.), On Individuality and Social Forms. Chicago: University of Chicago Press, pp. 143-150, 1971.

[25] G. Simmel, The Problems of the Philosophy of History: An Epistemological Essay, trans, G. Oakes, New York: Free Press, 1977.

[26] G. Simmel, Essays on Interpretation in Social Science, trans. G. Oakes, Totowa, NY: Rowman and Littlefield, 1980.

[27] N. Karakayali, "The uses of the stranger: Circulation, arbitration, secrecy, and dirt," Sociological Theory, vol. 24, issue 4, pp. 312-330, 2006.

[28] V. Marotta, "Georg Simmel, the Stranger and the Sociology of Knowledge," Journal of Intercultural Studies, vol. 33, pp. $675-689$, 2012.

[29] E. Murphy-Lejeune, Student Mobility and Narrative in Europe: The New Strangers. London: Routledge, 2002.

[30] R. Philip, “The return of 'The Stranger': Distance, proximity and the representation of identity in domain-specific discourse," ASp [Online] pp. 53-54, 2008.

[31] A. Lingis, The Community of Those Who Have Nothing in Common, Bloomington: Indiana University Press, 1994.

[32] B. Bertelsen and T. D. Bøe, "'He is quirky; He is the world's greates psychologist': On The Community of Those Who Have Nothing in Common,"Australian and New Zealand Journal of Family Therapy, vol. 37, issue 3, pp. 367-380, 2016.

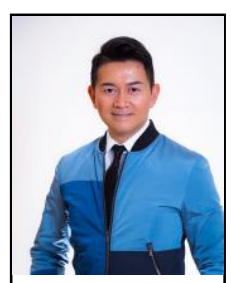

John Nguyet Erni is Fung Hon Chu Endowed Professor in Humanics, Chair Professor in Humanities, and Head of the Department of Humanities \& Creative Writing (2014-2020) at Hong Kong Baptist University. He is an elected Fellow of the Hong Kong Academy of the Humanities, and an elected Corresponding Fellow of the Australian Academy of the Humanities. In 
2017-18, Erni served as President of the Hong Kong Academy of the Humanities. A recipient of the Gustafson, Rockefeller, Lincoln, and Annenberg research fellowships, and other awards and grants, Erni has published widely on international and Asia-based cultural studies, human rights legal criticism, Chinese consumption of transnational culture, gender and sexuality in media culture, youth popular consumption in
Hong Kong and Asia, cultural politics of race/ethnicity/migration, and critical public health. He is the author or editor of 9 academic titles, more recently Law and Cultural Studies: A Critical Rearticulation of Human Rights (2019) and Visuality, Emotions, and Minority Culture: Feeling Ethnic (2017) 